\title{
A CONSTRUÇÃO FAMILIAR POR MEIO DA ADOÇÃO: REQUISITOS E MODALIDADES
}

\author{
FAMILY BUILDING THROUGH ADOPTION: REQUIREMENTS AND MODALITIES
}

\author{
Felipe do Amaral Scheuer
}

Universidade Regional do Noroeste do Estado do Rio Grande do Sul, Ijuí, RS, Brasil

\section{Daniel Hedlund Soares das Chagas}

Universidade Regional do Noroeste do Estado do Rio Grande do Sul, Ijuí, RS, Brasil

DOI: https://doi.org/10.46550/amormundi.v2i3.86

Recebido em: 14.02.2021

Aceito em: 20.03.2021

\begin{abstract}
Resumo: A adoçáo é um instituto muito importante do nosso ordenamento jurídico. O conceito de adoção, está presente na Constituição Federal de 1988, no ECA, no Código Civil, no Código de Processo Civil, na jurisprudência e também nas doutrinas, de formas diferentes. Através de uma pesquisa bibliográfica e documental o artigo tem o intuito de ponderar algumas questôes sobre a construção familiar por meio da adoção. A adoção é um processo afetivo e legal pelo qual uma criança ou adolescente passa a ser filho de um outro casal ou de uma única pessoa. Diante disso, o adulto adotante passa a ser pai ou mãe de uma criança que é gerada por outras pessoas. $\mathrm{O}$ ato de adotar é tornar alguém um filho, tanto pelo afeto, quanto pela lei, normalmente uma criança que nunca teve a proteção daqueles que a geraram. Quanto aos requisitos para a adoção, com a entrada em vigor do novo Código Civil, verifica-se que no artigo 42, caput, do ECA está uma das mudanças mais significativas quanto aos requisitos do adotante.
\end{abstract}

Palavras-chave: Família. Instrumento jurídico. Adoção.

Abstract: Adoption is a very important institute in our legal system. The concept of adoption is present in the Federal Constitution of 1988, in the ECA, in the Civil Code, in the Civil Procedure Code, in jurisprudence and also in doctrines, in different ways. Through bibliographical and documentary research, the article aims to ponder some questions about family construction through adoption. Adoption is an affective and legal process by which a child or adolescent becomes the child of another couple or a single person. Therefore, the adopting adult becomes the father or mother of a child that is generated by other people. The act of adopting is to make someone a child, both by affection and by the law, normally a child who never had the protection of those who generated it. As for the requirements for adoption, with the entry into force of the new Civil Code, it appears that in article 42, caput, of the ECA is one of the most significant changes regarding the requirements of the adopter.

Keywords: Family. Legal instrument. Adoption. 


\section{Consideraçóes iniciais}

Gonçalves (2012, p. 376), observa que "a adoção é um ato jurídico solene pelo qual alguém recebe em sua família, na qualidade de filho, pessoa a ela estranha”. Já Dias (2011) trata da questão do estado de filiação que acaba decorrendo de um fato que, nesse caso, seria o (nascimento) ou de um ato jurídico que seria à (adoçáo) - que ligado a esse ato jurídico em sentido estrito, tem uma eficácia condicionada à justiça. A adoção acaba criando um vínculo imaginário de maternidade ou paternidade e filiação entre as pessoas estranhas, coisas que são análogas e que resultam da filiação biológica. De acordo com Diniz (2009, p. 520 e 521):

A adoção vem a ser o ato jurídico solene pelo qual, observados os requisitos legais, alguém estabelece, independentemente de qualquer relação de parentesco consanguíneo ou afim, um vínculo fictício de filiação, trazendo para a sua família, na condição de filho, pessoa que, geralmente, lhe é estranha.

Para o autor supracitado, o entendimento de que a adoção deve observar os requisitos legais para tal, e assim analisados passam a estabelecer uma forma de parentesco tanto consanguíneo ou não, um vínculo irreal, fazendo com que traga o adotado (a) para o convívio da família, tornando-o filho, pessoa que até o presente momento era considerado um estranho.

Dias (2011) refere que a adoçáo acaba por construir um parentesco eletivo, pois é decorrente de um ato de vontade daquele que se habilita a adotar. A adoção passa a determinar que a paternidade só é verdadeira se ela decorre do desejo de amar e ser amado. Mas a sociedade ainda não vê dessa forma. De acordo com Diniz (2008), são nove os requisitos para a adoção.

O primeiro requisito fala da efetivaçáo por maior de 18 anos independentemente do estado civil (adoção singular), ou por casal (adoção conjunta), essa ligada por uma união estável ou pelo matrimônio, mas desde que um deles tenha completado 18 anos e comprovem estabilidade familiar. Cabe ressaltar também que ninguém pode ser adotado por duas pessoas, a não ser que sejam casadas ou vivam em união estável.

Os tutores e os curadores não estáo legitimados a adotar os seus tutelados e curatelados. Eles precisam primeiramente, prestar contas de sua administração, pois são fiscalizados pelo Ministério Público e julgadas pelo juízo competente [...] de acordo com o artigo 1.620 do CC.

O segundo requisito para poder adotar é a diferença mínima de idade que se exige entre o adotante e o adotado. Segundo o art. 1619 do Código Civil, a diferença tem que ser de pelo menos 16 anos mais velho a pessoa que for adotar, pela lógica de não poder conceber um filho de idade igual ou superior ao pai, ou a mãe. Tal exigência é para que os pais possam desempenhar seu poder familiar.

O terceiro requisito é o consentimento, tanto do adotado quanto de seus pais, nesse caso, se o adotado for menor de 12 anos, ou se for maior de idade, porém incapaz o seu representante legal, que pode ser o pai, tutor ou curador. Se a criança for maior de 12 anos, ela deve ser ouvida para manifestar sua concordância ou não sobre a adoção. Se os pais concordarem e deferirem a adoção em um procedimento próprio e autônomo, eles serão destituídos do poder familiar. A questão do consentimento é um ponto que tem que ser bem analisado, pois ele pode ser irrevogável. De acordo com Diniz (2009, p. 527):

O consentimento é revogável até a publicação da sentença constitutiva da adoção (CC art. 1.621, $\$ 2^{\circ}$ ). Pelo enunciado n. 259 do Conselho da Justiça Federal, aprovado na III Jornada de Direito \Civil: "a revogação do consentimento não 
impede, por si só, adoção, observado o melhor interesse do adotando". Pelo enunciado n. 110 do Conselho da Justiça Federal (aprovado na I Jornada de Direito Civil): é inaplicável o $\$ 2^{\circ}$ do art. 1.621 do novo Código Civil às adoçôes realizadas com base no Estatuto da Criança e do Adolescente.

O quarto requisito é a intervenção judicial na criação do menor. Este somente se aperfeiçoa diante de juiz, ou em um processo judicial, com a intervenção do Ministério Público, inclusive no caso da adoção de maiores de 18 anos. A competência para julgar processos de adoção de menores de 18 anos sempre será da Vara da Infância e Juventude.

O procedimento todo está na Lei n. 8.069/90. Depois da sentença judicial concessiva da adoção, ele passará a ter um efeito constitutivo e deverá ser inscrita no registro civil, mediante um mandado no qual será expedida a certidão. No registro vai o nome dos adotandos como pais. Depois a sentença conferirá ao adotado o nome do adotante e, a pedido deste, poderá modificar se quiser o prenome.

O quinto requisito bastante relevante na questão da adoção é a irrevogabilidade. Esse requisito diz que, mesmo que os adotantes tiverem filhos, os adotados também seráo equiparados a eles, ou seja, o adotado não perde seus direitos e deveres, seus compromissos com os seus pais ora adotandos, é o mesmo como se fossem filhos legítimos, inclusive direitos sucessórios, e proíbe qualquer tipo de discriminação relativo à filiação. A adoção é irreversível. Quando o adotado passa a integrar a família, é como se ele pertencesse a ela. Caso os pais do adotado morram, isso não restabelecerá o poder dos pais naturais.

O sexto requisito é relacionado também à questão do estágio de convivência entre os separados judicialmente ou extrajudicialmente e os divorciados no que se refere aos adotantes e adotando, caso esse tenha se iniciado na constância da sociedade conjugal. De acordo com o parágrafo único do art. 1.625 do Código Civil.

Parágrafo único. A adoção será precedida de estágio de convivência com o adotando, pelo prazo que o juiz fixar, observadas as peculiaridades do caso, podendo ser dispensado somente se o menor tiver menos do que um ano de idade ou se, independentemente de sua idade, já estiver na companhia do adotante durante tempo suficiente para a avaliação dos benefícios da constituição do vínculo.

O sétimo requisito refere-se ao acordo sobre a guarda e o regime de visitas que deve ser feito entre os divorciados e separados, tanto judicialmente quanto extrajudicialmente que pretendam adotar, conjuntamente, uma pessoa que com eles conviveu na vigência de seu casamento. Dispõe sobre isso o art. 1.622, parágrafo único, 2a parte do CC.

O oitavo requisito diz respeito à prestação de contas da administração e pagamento dos débitos por parte do tutor ou do curador que pretende adotar pupilo ou curatelado. Dispóe sobre o referido requisito o art. 1.620 do CC. E por fim, o último requisito é a comprovação da estabilidade familiar se no caso a adoção se der por conviventes, de acordo com o art. 1.618, parágrafo único, in fine.

\section{Metodologia}

O presente estudo compóe-se de uma pesquisa básica com revisão bibliográfica. A partir dos dados obtidos, realizou-se a análise e interpretação das informaçôes, mesclando-as de maneira 
a conseguir uma maior compreensão sobre o tema abordado.

\section{Discussáo teórica}

No Estatuto da Criança e do Adolescente existem duas espécies de família: a família natural e a família substituta. A primeira é formada pelos pais ou qualquer deles, pai ou mãe, e seus descendentes; a segunda, por ser considerada uma família substituta, ou seja, aquela que é feita a partir da guarda, tutela ou adoção. Os artigos 25 e 28 do referido ECA explicam as duas espécies de família:

Art. 25. Entende-se por família natural a comunidade formada pelos pais ou qualquer deles e seus descendentes. Parágrafo único. Entende-se por família extensa ou ampliada aquela que se estende para além da unidade pais e filhos ou da unidade do casal, formada por parentes próximos com os quais a criança ou adolescente convive e mantém vínculos de afinidade e afetividade.

Art. 28. A colocação em família substituta far-se-á mediante guarda, tutela ou adoção, independentemente da situação jurídica da criança ou adolescente, nos termos desta Lei.

De acordo com Edimara Sachet Risso e Michele Simone Algeri (2009) um dos primeiros princípios do ECA, diz que toda criança e adolescente deve ser criado e também educado em um meio considerado familiar e com muito afeto pela família natural. Sendo assim, essa afirmação não demonstra ser efetivada, mas a questão da colocação em família substituta em decorrência de maus-tratos, abandono, e outras formas que são consideradas indignas de vida.

\section{Modalidades de adoçáo}

\subsection{Adoçáo pronta}

Uma das modalidades ou espécie de adoção é a adoção pronta, ou adoção intuitu personae, que, segundo Edimara Sachet Risso e Michele Simone Algeri (2009), está estabelecida no artigo 166 do Estatuto da Criança e do Adolescente. Sendo assim, considerada uma adoção legal, pois está vinculada a tal artigo. De acordo com o artigo 166 do ECA:

A adoção legal trata da possibilidade de qualquer pessoa que manifeste em adotar, procurar o Juizado da Infância e da Juventude de sua cidade, com a finalidade de começar o procedimento de adoção de uma determinada criança que foi autorizada pelos pais biológicos a ser adotada.

Essa forma de adoção gera uma intermediaçáo entre os agentes envolvidos nela, que acabam acreditando que as pessoas consideradas mais pobres não têm capacidade para cuidar de suas próprias vidas, quanto mais de um filho. Com isso, o esforço, o envolvimento dos agentes que participam desse procedimento, acaba que o mínimo de esforço é envolvido e investido nesses programas de dar a assistência devida a essas famílias, que acabam por serem desvalorizadas e com isso entregando seus filhos para outra família criar. De acordo com Edimara Sachet Risso e Michele Simone Algeri (2009, p. 52):

Existe certo risco nesta prática se, decorrido algum tempo, a mãe ou o pai vem a se arrepender da decisão tomada, ou se ocorrem mudanças favoráveis em suas vidas e pretendem reaver seu filho. São situaçôes dramáticas, pois geralmente a 
criança foi adotada por uma família que realmente mantém todos os cuidados e dispensa enorme afeto a elas. O risco a que se referiu é com relação ao sentimento de arrependimento, porque, no que tange à legalidade, não há o que se discutir, vez que os atos foram praticados em conformidade com a norma, o que confere segurança aos pais adotivos, tendo em vista, inclusive, que nenhuma decisão por parte do Judiciário é tomada em prejuízo das partes envolvidas ou que viole os direitos humanos.

Essa espécie de adoção não será possível na modalidade de adoção internacional, vez que a criança tem que estar sob a responsabilidade do Estado para poder ser adotado por um casal ou pessoa estrangeira.

\subsection{Adoção "à brasileira"}

Segundo Risso e Algeri (2009), a adoção “à brasileira” é considerada uma fraude ao nosso ordenamento jurídico, praticada em desconformidade com as normas exigidas para o processo de adoção. Já para Dias (2011):

Há uma prática disseminada no Brasil- daí o nome eleito pela jurisprudência- de o acompanhante de uma mulher perfilhar o filho dela, simplesmente registrando a criança como se fosse seu descendente. Ainda que este agir constitua crime contra o estado de filiação (CP 242), não tem havido condenaçôes, pela motivação afetiva que envolve essa forma de agir.

Essa modalidade de adoção ilegal ocorre quando a criança é dada pelos pais ou pela mãe para uma família conhecida. Muitas vezes há boa-fé de ambas as partes, pois há contatos frequentes da família que adotou e até auxílio financeiro à mãe biológica.

Nesse procedimento, muitos registram a criança junto ao Cartório de Registro de Pessoas Naturais, pois os "novos" pais irão registrar tal criança como se fosse filho deles, da forma normal, mas isso acaba gerando um "falso" registro da criança ou do menor. De acordo com Edimara Sachet Risso e Michele Simone Algeri (2009, p. 53):

A jurisprudência vem adotando o entendimento de que a adoçáo à brasileira, embora presente o gesto de afeição maternal ou paternal com significativo valor social, constitui crime, em especial contra a fé pública, no que se refere a documentos públicos e o que neles se contém. Mas, sempre que possível aplicando o perdão judicial.

Conforme entendimento jurisprudenciais, com a inovação do parágrafo único do art. 242 do Código Penal, se mantém a proteção à fé pública, e também é levada em consideração a redução da pena do delito que possibilitou a aplicação do perdão judicial. Não acontece a absolviçáo da pessoa que cometeu o delito, mas tem que a pena ser aplicada, mesmo com o perdão judicial.

\subsection{Adoção internacional}

De acordo com Maria Berenice Dias (2011), a adoção internacional é aquela que gera a possibilidade de crianças e adolescentes serem adotados por uma família estrangeira, mas que podem perder sua nacionalidade. Ainda há quem considere esse tipo de adoção uma adoção que agrega muita valia, pois ela pode amenizar os problemas sociais.

No entanto a adoção deve ter como finalidade primordial atender a uma política social 
de proteção à infância, por isso independe de onde sejam os adotantes, se de outros países ou do próprio país. Trata-se de uma adoção admitida constitucionalmente, na qual é delegada à lei o que é estabelecido dos casos e das condiçóes de sua referida efetivação por estrangeiros como estabelece o artigo 227, $\$ 5 .^{\circ}$ da Constituição Federal.

O referido artigo menciona os deveres da família, que tem que assegurar à criança, ao adolescente os direitos básicos, e protegê-los de toda forma de negligência, discriminação, exploração, crueldade, violência e opressão. Cabe também mencionar que a adoção pelos casais ou pessoas estrangeiras será devidamente assistida pelo Poder Público, na forma da lei. De acordo com Venosa (2012):

O envio de crianças brasileiras para o exterior somente é permitido quando houver autorização judicial. Desse modo, na adoção por pessoa residente ou domiciliada fora do país, aspecto que traz maior esfera de problemas nessa matéria, nunca será dispensado o estágio, que será cumprido no território nacional, com duração mínima de 30 dias (art. 46, $\$ 3^{\circ}$ ). A adoção internacional, mais suscetível a fraudes e ilicitudes, é dos temas mais delicados, sujeito a tratados e acordos internacionais e a reciprocidade de autoridades estrangeiras. Procura-se minimizar a problemática do tráfico de crianças. $\mathrm{O}$ estrangeiro, domiciliado no Brasil, submete-se às regras nacionais de adoção e pode adotar, em princípio, como qualquer brasileiro.

A orientação que o Magistrado deve nortear, é que toda e qualquer tipo de adoção, por si só deva ser encarada de uma forma de exceção, uma saída, para que os adotandos desamparados ou em estado de abandono sejam adotados. Pois sendo assim visto, vai acabar deixando de lado esse preconceito nacional quanto aos estrangeiros que querem adotar uma criança, mas os estrangeiros não podem deixar de obedecer a todos os requisitos que lhes são básicos e imprescindíveis para a adoção.

\subsection{Adoção póstuma}

A adoção póstuma, segundo Galdino Augusto Coelho Bordallo (2009, p. 219), "é a que se concede após a morte do adotante, desde que este tenha manifestado, de forma inequívoca, seu desejo de adotar".

De acordo com a previsão legal da referida adoção, basta a inequívoca manifestação de vontade do adotante para que o processo, após a morte do adotante, prossiga até seu termo, com o julgamento de mérito. Para isso, basta que o processo de adoção tenha dado entrada antes da morte do adotante, com a manifestação de sua expressa vontade. Dias (2011, p. 495) assevera que:

A sentença de adoção possui eficácia constitutiva e seus efeitos começam a fluir a partir do trânsito em julgado da sentença (ex nunc), não produzindo efeito retroativo (ECA $47 \$ 7 .^{\circ}$ ). Contudo, a lei abre exceçáo na hipótese do falecimento do adotante, no curso do processo: o efeito da sentença retroage à data do falecimento. Paulo Lôbo justifica: o óbito faz cessar a personalidade e nenhum direito pode ser atribuído ao morto, sendo a retroatividade excepcional, no interesse do adotando.

O deferimento dessa modalidade de adoção está diretamente condicionado à propositura da ação, como trata o artigo $42, \$ 6^{\circ}$ do ECA.

De acordo com Dias (2011), a Justiça e os tribunais apenas convalidam o desejo do falecido. Dá para ser tratada como uma adoção nuncupativa, e acaba por se operar concomitantemente 
ligada à extinção do poder familiar que existe e a devida constituição do vínculo gerado de filiação civil. É de se admitir também a adoção póstuma quando a vontade do adotante estiver expressa em seu testamento, pois evidencia a sua intenção de adotar.

\subsection{Adoçáo tardia}

De acordo com Marlizete M. Vargas (2015), o termo "tardia” é utilizada para definir a adoção de crianças maiores. O termo utilizado "maior" é para diferenciar que a criança não é mais tida como um bebê, ela começa a se tornar uma pessoa "independente", não necessitando de que os pais o estejam acompanhando em todos os momentos.

Alguns autores consideram a faixa etária, numa adoção tardia, a idade entre dois e três anos como uma margem entre a adoção precoce e a adoção tardia. Outros fatores envolvem esse tipo de avaliação, como o tempo que essas crianças permanecem numa instituição, lares e abrigos e quais os seus níveis de desenvolvimento.

O que pode acontecer é que as crianças de dois ou três anos ainda não apresentem comportamentos compatíveis com sua idade, como não andarem sozinhas, não falarem, usarem fraldas. Com isso a adaptação delas numa família não apresentará características de uma adoção tardia, como as fases de comportamentos em que se manifestam agressivos ou regressivos, pois isso, a maioria das crianças adotadas acabam passando.

É uma questão muito importante avaliar a prontidão dos adotantes e da criança para constituir uma nova família. Segundo Vargas (2015):

Como foi o processo de aproximação da criança com a família? É importante que a criança deseje ir viver com a família, que esteja disposta a aceitálos. Ela é encaminhada pelos profissionais encarregados de operar a sua adoção por aquele(s) adotante(s), é escolhida por ele(s), mas deve manifestar sua vontade, deve ser ativa no processo de aceitação daquela(s) pessoa(s) como seus pais. Nesse processo, é fundamental a atitude do adotante, de se mostrar disponível para ser adotado pela criança numa postura mais passiva do que ativa. A criança necessita se sentir livre para a sua escolha e, ao mesmo tempo, segura de que é querida, é aceita. Isso nem sempre acontece nas primeiras semanas ou meses de convivência. A angústia dos pais, ante a incerteza de ser aceito pelo filho, que ainda resiste a lhe chamar de pai/mãe, muitas vezes, pode ser o passo inicial para as dificuldades de adaptação da criança numa família. A aproximação paulatina entre criançafamília também pode operar o ajuste necessário entre a criança idealizada e a criança que está ali para ser adotada, que já tem traços bem definidos, além de uma história e de hábitos adquiridos em relaçóes anteriores. A criança também precisa adaptar-se aos novos modelos de pais. Muitas vezes a instituição reforça uma super idealização da família adotiva.

As crianças que sofrem muito com a perda dos vínculos com a família biológica, são as mais vulneráveis e que vão sofrer muito com uma adaptação ao seu novo ambiente familiar. Essas dificuldades para estabelecer novos vínculos afetivos, com os novos pais poderão ser bem maiores, ou até intransponíveis, naquele real momento com aquela família, ou mesmo permanentes.

Importante ressaltar também o tempo e as condiçóes em que a criança ou o adolescente ficou abrigado. Nas instituiçóes, tem-se uma cultura de igualar todas as crianças, e assim acabam não tratando algumas questôes consideradas dolorosas, pois elas já sofreram muitas perdas antes de ingressarem nos lares provisórios. De acordo com Vargas (2015): 
Quanto maior o tempo da permanência da criança num abrigo, maior poderá ser o risco dela vir a ter dificuldades na adaptação numa família. Por outro lado, quanto mais tarde ocorrer a institucionalizaçáo e quanto mais próximo de um lar forem as características do abrigo, menores poderão ser esses riscos. $\mathrm{O}$ que se observa é que muitos abrigos funcionam ainda como depósitos de crianças. Estando lá, as crianças estáo isoladas do mundo num ambiente bastante pobre em estimulação essencial para o desenvolvimento normal de suas potencialidades.

Essas crianças acabam por não aprender a desempenhar o papel deles de filho. Eles se sentem como participantes de um grupo que desempenha todas as funções e as necessidades consideradas básicas dos seus membros, que acabam se relacionando com seus papéis de casal, pais/filhos e irmáos. Por isso necessitam de um período para aprenderem a desempenhar o seu papel na família que os adotar. Esse processo pode variar muito de criança para criança, e independe de idade.

\subsection{Adoçâo por casais homoafetivos}

Segundo Dias (2011), a adoção por casais homoafetivos é bem tormentosa e divide muitas opiniōes. Mesmo assim, é crescente o número de gays e lésbicas que se candidatam à adoção de forma individual.

A adoção por casais do mesmo sexo começou a ser concedida de forma tímida, sem que o parceiro ou a parceira tivesse que esconder sua orientação sexual quando se habilitasse para adoção. O que causa um pouco de curiosidade e espanto é a questão de, quando se faz a habilitação, não se perguntar se a pessoa mantém um relacionamento homoafetivo.

Isso causa certa estranheza, pois o estudo social não é feito com o parceiro, e acaba deixando de prestar a atenção para o fato de que a criança está indo viver num ambiente constituído por pessoas do mesmo sexo. Essa habilitação é deficiente, considerada uma habilitação incompleta, pois deixa de ver vários interesses que são de suma importância e interesse do adotando. De acordo com Dias (2011, p. 499):

Por outro lado, diante do conceito aberto de família substituta (ECA 28), nada impede que duas pessoas adotem independente da identidade sexual. Nem na Lei dos Registros Públicos se encontra óbice ao registro que indique como genitores duas pessoas do mesmo sexo. Basta registrar o adotando como "filho de", acrescentando o nome dos pais. No entanto, em alguns Estados, permanece a resistência em conceder a adoção ao casal que mantém união homoafetiva. As justificativas são muitas: problemas que a criança poderia enfrentar no ambiente escolar; ausência de referencias de ambos os sexos para o desenvolvimento do adotando; obstáculos na Lei dos Registros Públicos, entre outros. Mas o motivo é um só: o preconceito. É enorme a dificuldade em aceitar os pares do mesmo sexo como família. Há a crença de que se trata de relacionamento isento de perfil de retidão e moralidade. Isso tem o nome de discriminação. A aparente intenção de proteger as crianças só os prejudica. Vivendo em uma família homoafetiva e possuindo vínculo jurídico com somente um do par, resta absolutamente desamparado com relação ao outro, que também considera pai ou mãe, mas que não tem os deveres decorrentes do poder familiar. $\mathrm{O}$ não estabelecimento de uma vinculaçáo obrigacional gera a absoluta irresponsabilidade de um dos genitores para com o filho que também é seu.

Não se pode admitir a não possibilidade de o filho biológico ser adotado pelo parceiro do genitor. De certo modo, é permitido que um dos cônjuges ou companheiros adote sim o filho 
do outro, conforme dispóe o artigo 41, $\$ 1^{\circ}$ do ECA. E por se tratar de uma adoção de casais que mantêm uma relação homoafetiva, também não impede a possibilidade de o adotando ser adotado pelo companheiro de seu pai ou mãe.

Já para Galdino Augusto Coelho Bordallo (2009), a questão da adoção por casais homoafetivos é uma das mais discutidas no meio jurídico, sendo um ponto a ser analisado pela doutrina civil que acaba encontrando pontos favoráveis e desfavoráveis à adoção por casais homossexuais. Segundo o Autor (2009, p. 187):

Antes de adentrarmos ao tema cabe ressaltar não haver nenhum empecilho à adoção fincado na opçáo sexual do adotante. Inicialmente eram julgados improcedentes os pedidos de adoção quando vinha à tona a preferência sexual do requerente, sob o fundamento de que a vida que o adotante levaria e os exemplos que a criança/adolescente teriam na convivência doméstica seriam prejudiciais para o seu desenvolvimento como pessoa. Com o passar do tempo este posicionamento foi sendo alterado e passaram a ser concedidas adoçōes, independente da opção sexual do adotante, orientados por estudos e pareceres psicológicos e psiquiátricos de que a orientação sexual dos pais náo influencia a dos filhos. Com bases no princípio da dignidade humana, igualdade e não-discriminação, os tribunais passaram a conceder as adoçóes. [...].

Diante de tantos avanços jurídico-científicos, Dias (2009) diz que em torno da questão da homossexualidade e das uniôes de casais homoafetivos, não se pode deixar de perceber a importância de um pedido de adoção ser validado. Se um pedido de adoção é negado sem analisar viabilidade desse pedido, ele acaba se tornando uma decisão preconceituosa ou, no mínimo, com falta de informaçóes adequadas.

\section{Consideraçóes finais}

Não se pode deixar de lado tudo que está sendo e vem sendo construído, em sede jurisprudencial e doutrinária, sobre toda a questão que envolvem os vínculos de parentalidade. Há uma fila enorme de pessoas querendo adotar ou querendo alguém para ser chamado de pai ou mãe. Não importa a forma como essa família é constituída, ou seja, um pai e uma mãe, dois pais, duas mães, somente o pai ou somente a mãe. O importante é a afetividade que está envolvida nessa relação. Muitas pessoas não podem ter seus filhos naturais, assim como inúmeras crianças e adolescentes foram abandonados ou dados para a adoção, por seus pais biológicos. Negar o direito de pessoas adotares, ou tornar o processo de adoção burocrático, a ponto de uma desistência, é furtar desses indivíduos a capacidade de doar-se como mãe/pai ou como filho a aquele que não teve essa oportunidade.

A questão diz respeito à possibilidade de adoção de crianças e adolescentes por parte daqueles que não puderam ter filhos ou que mesmo com seus filhos naturais, ainda assim, num gesto de amor ao próximo, resolvem trazer para seus lares, um novo membro que antes se encontrava em situação de vulnerabilidade física e emocional, proporcionando-lhe a possibilidade de uma vida digna e um futuro melhor. Não se pode olvidar que as crianças e adolescentes retiradas de sua família natural, seja pelo motivo que for, traz consigo uma carga dolorosa muito grande. Porém, a adoção, antes de mais nada, representa um ato de amor, desprendimento. Quando efetivada com o objetivo de atender aos interesses do menor, é um gesto de humanidade.

Por qualquer ângulo que se analise a questão da adoção, é imprescindível que as 
mudanças legislativas ocorram com a maior brevidade possível, pois as crianças e adolescentes que conseguem uma família não podem ser punidas pelo preconceito e pela covardia de nossos legisladores, pois está claro que o Judiciário solucionará os casos que lhes forem apresentados. Essas famílias são consideradas famílias que atendem a uma função social, deixando claro que a construção de famílias assim está sendo feita de uma forma coerente, e sendo analisada tanto pelo Poder Judiciário, quanto pelos demais órgáos responsáveis pela proteção de crianças e adolescentes.

\section{Referências}

BERGAMINI, N. B. B. \& BERTHOUD, C. M. E. A família em fase de aquisição. Em C. M. Cerveny \& C. M. E. Berthoud (Orgs.). "Família e ciclo vital: nossa realidade em pesquisa" (pp. 49-73). São Paulo: Casa do Psicólogo. 1997.

DIAS, Maria Berenice. Uniáo Homossexual: o preconceito \& a justiça. Porto Alegre: Livraria do Advogado, 2001.

DINIZ, Maria Helena. Curso de Direito Civil Brasileiro: Direito de Família. 24. ed. reformulada. São Paulo: Saraiva, 2009. 5 v.

GIDDENS, Anthony. $\mathbf{O}$ mundo em descontrole: o que a globalização está fazendo de nós. Rio de Janeiro: Record. 2000.

GRANATTO, Eunice Ferreira Rodrigues. Adoção: doutrina e prática (com comentários à nova Lei de Adoçáo Lei 12.010/09). Curitiba: Imprenta. 2010.

GROPPO, Luís Antônio. Juventude. Ensaios sobre sociologia e história das juventudes modernas. Rio de Janeiro: Difel. 2000.

ISHIDA, Valter Kenji. Estatuto da Criança e do Adolescente: doutrina e jurisprudência. 14 ed. São Paulo: Atlas, 2013.

VENOSA, Silvio Salvo. Direito das Sucessóes, Vol. 7. 13a ed. São Paulo, Atlas: 2013.

VENOSA, Silvio Salvo. Lei n. 8.069, de 13 de julho de 1990. Dispóe sobre o Estatuto da Criança e do Adolescente e dá outras providências. Disponível em: http://www.planalto.gov.br/ ccivil_03/Leis/L8069.htm. Acesso em Acesso em: 30/11/2013.

SILVA, Tânia Pereira. Direito da criança e do adolescente: uma proposta interdisciplinar. Rio de Janeiro: Renovar, 2008. 